\title{
Defective macrophage phagocytosis of bacteria in COPD
}

\author{
A.E. Taylor*, T.K. Finney-Hayward*, J.K. Quint ${ }^{*}$, C.M.R. Thomas*, S.J. Tudhope*, \\ J.A. Wedzicha ${ }^{\#}$, P.J. Barnes* and L.E. Donnelly*
}

ABSTRACT: Exacerbations of chronic obstructive pulmonary disease (COPD) are an increasing cause of hospitalisations and are associated with accelerated progression of airflow obstruction. Approximately half of COPD exacerbations are associated with bacteria and many patients have lower airways colonisation. This suggests that bacterial infection in COPD could be due to reduced pathogen removal. This study investigated whether bacterial clearance by macrophages is defective in COPD.

Phagocytosis of fluorescently labelled polystyrene beads and Haemophillus influenzae and Streptococcus pneumoniae by alveolar macrophages and monocyte-derived macrophages (MDM) was assessed by fluorimetry and flow cytometry. Receptor expression was measured by flow cytometry.

Alveolar macrophages and MDM phagocytosed polystyrene beads similarly. There was no difference in phagocytosis of beads by MDM from COPD patients compared with cells from smokers and nonsmokers. MDM from COPD patients showed reduced phagocytic responses to $S$. pneumoniae and $\boldsymbol{H}$. influenzae compared with nonsmokers and smokers. This was not associated with alterations in cell surface receptor expression of toll-like receptor (TLR)2, TLR4, macrophage receptor with collagenous structure, cluster of differentiation (CD)163, CD36 or mannose receptor. Budesonide, formoterol or azithromycin did not suppress phagocytosis suggesting that reduced responses in COPD MDM were not due to medications.

COPD macrophage innate responses are suppressed and may lead to bacterial colonisation and increased exacerbation frequency.

KEYWORDS: Budesonide, formoterol, Haemophillus influenzae, monocyte-derived macrophage, phagocytosis, Streptococcus pneumoniae

hronic obstructive pulmonary disease (COPD) is an inflammatory lung disease, comprising small airways disease and emphysema [1]. It is currently the sixth most common cause of death globally and is predicted to become the third most common cause of death by 2020 [2]. This may be due to the increased incidence of cigarette smoking, as this is the most common risk factor for COPD and contributes to $\sim 85 \%$ of all cases. Approximately $15 \%$ of smokers will develop COPD, whereas the incidence in nonsmokers is $1.6 \%$ [3]. In healthy individuals and smokers without lung obstruction, the lower airways are sterile, but in COPD patients there is often colonisation of the lower respiratory tract, with Streptococcus pneumoniae and Haemophilus influenzae being the most common bacterial pathogens [4]. Exacerbations of COPD are an increasing cause of hospitalisation in the UK [5], are associated with accelerated disease progression [6] and account for much of the healthcare costs associated with COPD $[7,8]$. The causes of exacerbations vary but $\sim 50 \%$ of infective exacerbations are bacterial in origin. Alveolar macrophages contribute $90-95 \%$ of cells found in bronchoalveolar lavage fluid (BALF) and are highly phagocytic, producing multiple inflammatory mediators [9]. Moreover, their role in removal of potentially pathogenic microorganisms via phagocytosis is essential in maintaining the normally sterile environment within the lung. One reason for the increased incidence of bacterial infections in the respiratory tract of COPD patients might be failure of macrophages

This article has supplementary material accessible from www.erj.ersjournals.com

AFFILIATIONS

*Airways Disease Section, National Heart and Lung Institute, Imperial College London, and ${ }^{\#}$ Academic Unit of Respiratory Medicine, Royal Free and University College Medical School, University College London, London, UK.

CORRESPONDENCE

L.E. Donnelly

Airways Disease Section

National Heart and Lung Institute

Dovehouse Street

London

UK

E-mail: I.donnelly@imperial.ac.uk

Received:

March 042009

Accepted after revision:

Oct 152009

First published online:

Nov 062009 
to clear pathogens because of reduced phagocytosis due to chronic activation $[10,11]$.

Alveolar macrophages from COPD patients phagocytose fewer apoptotic epithelial cells [12] and Escherichia coli [13] compared with nonsmokers and less $H$. influenzae compared with smokers without COPD [14]. Presently, there are no animal models of this aspect of COPD, limiting study to primary human cells. Therefore, we compared the phagocytic responses of alveolar macrophages and monocyte-derived macrophages (MDM) from COPD patients with cells from nonsmokers and smokers without lung obstruction. The use of MDM examined whether reduced phagocytic response of alveolar macrophages in COPD was due to these cells becoming replete or whether differentiation in a specific, pro-inflammatory, lung environment was required to establish this defect.

\section{METHODS}

\section{Subject selection}

Healthy subjects and smokers were recruited from the National Heart and Lung Institute, Royal Brompton Hospital, London (UK). COPD subjects were recruited from the Royal Free Hospital, London or Wexham Park Hospital, Slough (UK). All subjects gave written informed consent as approved by the Royal Brompton and Harefield NHS Trust Ethics Committee (London, UK). BALF was obtained from consenting patients at St. Mary's Hospital, London (UK) or Wexham Park Hospital. Demographic data are presented in table 1. COPD patients were significantly older than the control groups but there were no differences in smoking history with the smoking controls (table 1).

\section{Cell culture}

Monocytes were isolated from PBMC using a Monocyte Isolation kit II (Miltenyi Biotec, Surrey, UK) and cultured in the presence of $2 \mathrm{ng} \cdot \mathrm{mL}^{-1}$ granulocyte-macrophage colonystimulating factor (GM-CSF) for 12 days to generate MDM as described previously [15]. Alveolar macrophages were isolated from BALF as described previously [16].

\begin{tabular}{|c|c|c|c|}
\hline & Nonsmokers & Smokers & COPD \\
\hline Subjects $n$ & 20 & 17 & 19 \\
\hline Age yrs & $48 \pm 3$ & $53 \pm 2$ & $70 \pm 2^{9++}$ \\
\hline Sex M/F n & $11 / 9$ & $10 / 7$ & $11 / 8$ \\
\hline $\begin{array}{c}\text { Smoking history } \\
\text { pack-yrs }^{\#}\end{array}$ & $0.0 \pm 0.0^{+}$ & $33.3 \pm 4.6$ & $45.0 \pm 4.9^{\circ}$ \\
\hline FEV 1 L & $3.3 \pm 0.15$ & $2.9 \pm 0.3$ & $1.2 \pm 0.1^{9+}$ \\
\hline FEV $1 \%$ pred & $102.7 \pm 2.6$ & $93.8 \pm 3.8$ & $50.6 \pm 4.0^{\bullet++}$ \\
\hline FVC L & $4.2 \pm 0.2$ & $3.8 \pm 0.3$ & $2.4 \pm 0.3^{9+}$ \\
\hline FEV $1 / F V C$ & $0.8 \pm 0.03$ & $0.8 \pm 0.02$ & $0.5 \pm 0.03^{\bullet++}$ \\
\hline \multicolumn{4}{|c|}{$\begin{array}{l}\text { Data are presented as mean } \pm \text { SEM, unless otherwise stated. COPD: chronic } \\
\text { obstructive pulmonary disease; M: male; F: female; FEV1: forced expiratory } \\
\text { volume in } 1 \mathrm{~s} \text {; \% pred: \% predicted; FVC: forced vital capacity. }{ }^{\#}: 1 \text { pack-yr } \\
\text { represents } 20 \text { cigarettes per day for } 1 \mathrm{yr} .{ }^{\imath}: \mathrm{p}<0.001 \text { versus nonsmokers; }{ }^{+} \text {. } \\
\mathrm{p}<0.001 \text { versus smokers. }\end{array}$} \\
\hline
\end{tabular}

\section{Phagocytosis assays}

Non-typeable $H$. influenzae strain 1479 and S. pneumoniae serotype 9V strain 10692 were cultured and heat killed at $60^{\circ} \mathrm{C}$ for $2 \mathrm{~h}$. Bacteria were fluorescently labelled using Alexafluor 488 dye $\left(2 \mathrm{mg} \cdot \mathrm{mL}^{-1}\right.$ in dimethyl sulfoxide) in the dark, at room temperature overnight. The labelled bacteria were washed repeatedly in PBS to remove unbound label and resuspended in PBS. For alternative experiments, live bacteria were resuspended in broth containing CellTracker Red CMPTX dye $(12.5 \mu \mathrm{M})$ (Molecular Probes, Invitrogen Ltd, Paisley, UK) and incubated in the dark at $37^{\circ} \mathrm{C}$ for $45 \mathrm{~min}$. The labelled bacteria were washed in Dulbecco's-PBS (D-PBS), until the free dye was removed, and stored at $-20^{\circ} \mathrm{C}$. Fluorescently labelled polystyrene beads or bacteria were added to cells and incubated for the times indicated. Cells were washed with D-PBS and fluorescence of extracellular particles was quenched by adding Trypan blue ( $2 \%$ (volume/volume)) for $1 \mathrm{~min}$. Excess fluid was removed and fluorescence determined for beads and heat-killed bacteria using an excitation $\lambda 480 \mathrm{~nm}$ and emission $\lambda 520 \mathrm{~nm}$. For experiments using live bacteria, MDM were exposed for $4 \mathrm{~h}$ prior to measurement in a platereader using an excitation $\lambda 570 \mathrm{~nm}$ and emission $\lambda 610 \mathrm{~nm}$. Initial experiments and pharmacology experiments with $E$. coli
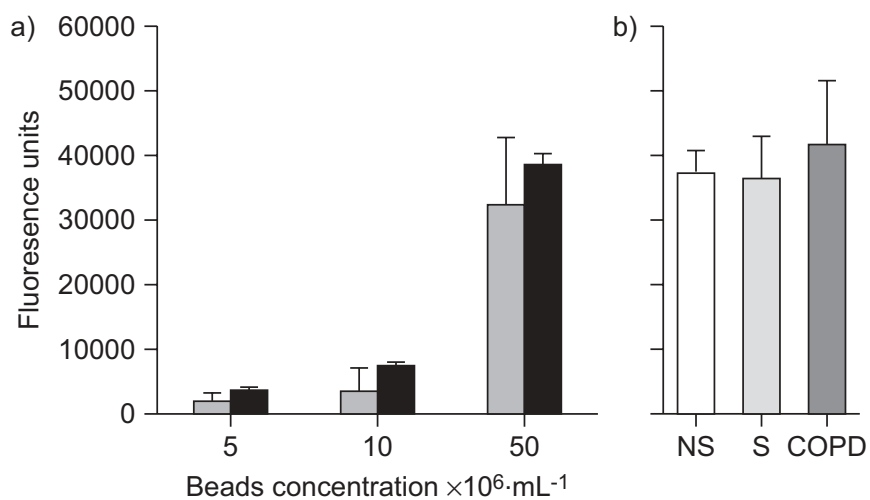

c)

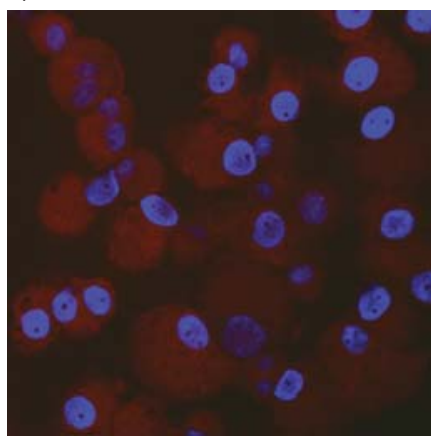

No beads

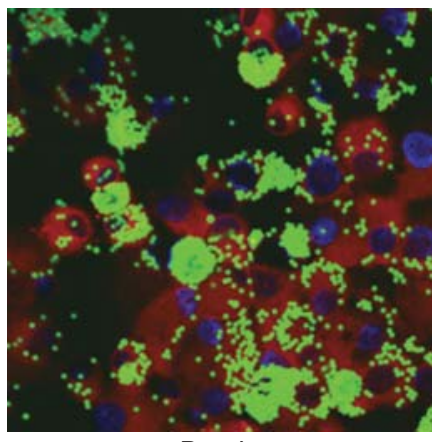

Beads

FIGURE 1. Comparison of alveolar macrophage and monocyte-derived macrophages (MDM) phagocytosis of beads. a) Alveolar macrophages ( $\square$ ), $n=7$ and $\operatorname{MDM}(\boldsymbol{\square}) n=7$, were exposed to fluorescent beads for $6 \mathrm{~h}$. Phagocytosis was measured using a fluorometric plate reader. b) Comparison of phagocytic capacity of MDM from nonsmokers (NS; $\square ; n=9$ ), smokers (S; $; n=13$ ) and chronic obstructive pulmonary disease (COPD) patients ( $\square ; n=10$ ), following exposure to $50 \times 10^{6}$ beads $\cdot \mathrm{mL}^{-1}$ for $6 \mathrm{~h}$. Data are presented as mean $\pm \mathrm{SEM}$. c) Confocal micrograph of MDM engulfing fluorescent beads $\left(50 \times 10^{6}\right.$ beads $\left.\cdot \mathrm{mL}^{-1}\right)$. 

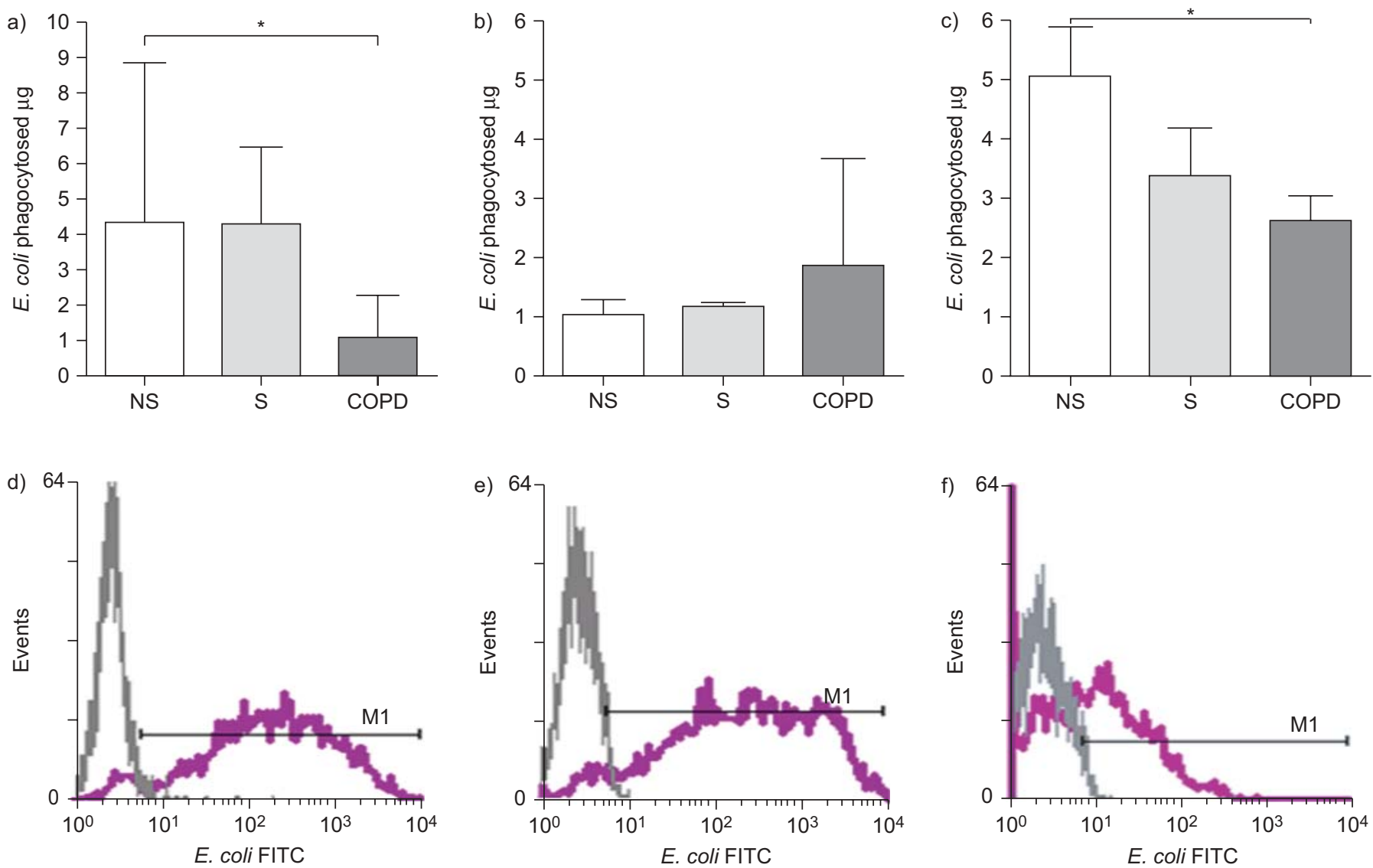

FIGURE 2. Phagocytosis of Escherichia coli by a) alveolar macrophages, b) monocytes and c) monocyte-derived macrophages (MDM) from nonsmokers (NS; $\square$ ), smokers (S; $\square$ ) and chronic obstructive pulmonary disease (COPD) patients ( $\square$ ) following exposure to $1 \mathrm{mg} \cdot \mathrm{mL}^{-1}$ FITC-E. coli for $1 \mathrm{~h}$. a) NS: $\mathrm{n}=5 ; \mathrm{S}: \mathrm{n}=5 ; \mathrm{COPD}$ : $\mathrm{n}=4$. b) NS: $n=4 ; S: n=4 ;$ COPD: $n=6$. c) NS: $n=7 ; S: n=6 ; C O P D: n=8$. Data are presented as median \pm interquartile range. ${ }^{*}: p<0.05$. The phagocytic response of MDM to fluorescently labelled $E$. coli was also determined by flow cytometry for d) NS, e) $\mathrm{S}$ and f) COPD patients. Data are presented as a representative fluorescence-activated cell sorting histogram, in which the grey lines are cells in the absence of bacteria and the purple lines are cells in the presence of bacteria for at least four independent experiments.

were performed using the Vybrant Phagocytosis kit (Invitrogen Ltd) according to the manufacturer's instructions. Data are presented as phagocytosis relative to the fluorescence of each specific bacterium to account for differences in labelling. In order to confirm the labelling procedure was not altering the ability of cells to phagocytose, E. coli (strain K12; Sigma, Poole, UK) were labelled under identical conditions and used in comparative experiments. Alternatively, following exposure of cells to bacteria as described above, cells were removed from the plate by agitation and fluorescence measured using a flow cytometer.

\section{Confocal microscopy}

Macrophages were cultured on Lab-tek Permanox (Nunc, Loughborough, UK) chamber slides and fixed with $4 \%$ (weight/volume) paraformaldehyde. Nuclei were stained with DAPI (4',6-diamidino-2-phenylindole) and cell cytoplasm by incubation with Evans blue dye $(0.1 \%(\mathrm{w} / \mathrm{v}))$. Slides were viewed on a Leica TCS 4D Confocal microscope with a Krypton-Argon laser to detect fluorescence of the FITC (fluorescein isothiocyanate)/yellow-green/Alexafluor 488 fluorochromes. Images of the three stains (DAPI (blue), Evans Blue (red) and the fluorochromes (green)) were overlaid.

\section{Electron microscopy}

MDM were incubated with $H$. influenzae $\left(1 \mathrm{mg} \cdot \mathrm{mL}^{-1}\right.$, for $\left.1 \mathrm{~h}\right)$ and fixed by addition of glutaraldehyde. Secondary fixation was performed with osmium tetroxide. Samples were then suspended in molten $2 \%(\mathrm{w} / \mathrm{v})$ agar and dehydrated by incubation with increasing concentrations of methanol. Cells were infiltrated with propylene oxide and Araldite resin, followed by incubation and embedding in Araldite alone. Ultrathin sections were then cut, mounted on copper support grids and stained using uranyl acetate and Sato's lead citrate. Grids were transferred to the TEM for visualisation.

\section{Flow cytometric analysis of macrophage receptor expression}

MDM were removed from the cell culture plates using nonenzymatic cell dissociation solution (Sigma), washed in PBS containing $0.5 \%(\mathrm{w} / \mathrm{v})$ bovine serum albumin (BSA) and $0.1 \%$ $(\mathrm{w} / \mathrm{v})$ sodium azide $(\mathrm{PAB})$ and then resuspended at a concentration of $1 \times 10^{6} \mathrm{~mL}^{-1}$. MDM suspension $(180 \mu \mathrm{L})$ was incubated for $1 \mathrm{~h}$ on ice with $20 \mu \mathrm{L}$ of either the appropriate mouse isotype control antibody, or mouse monoclonal antibody against cluster of differentiation (CD)14, CD163, CD36, mannose receptor, macrophage receptor with collagenous 

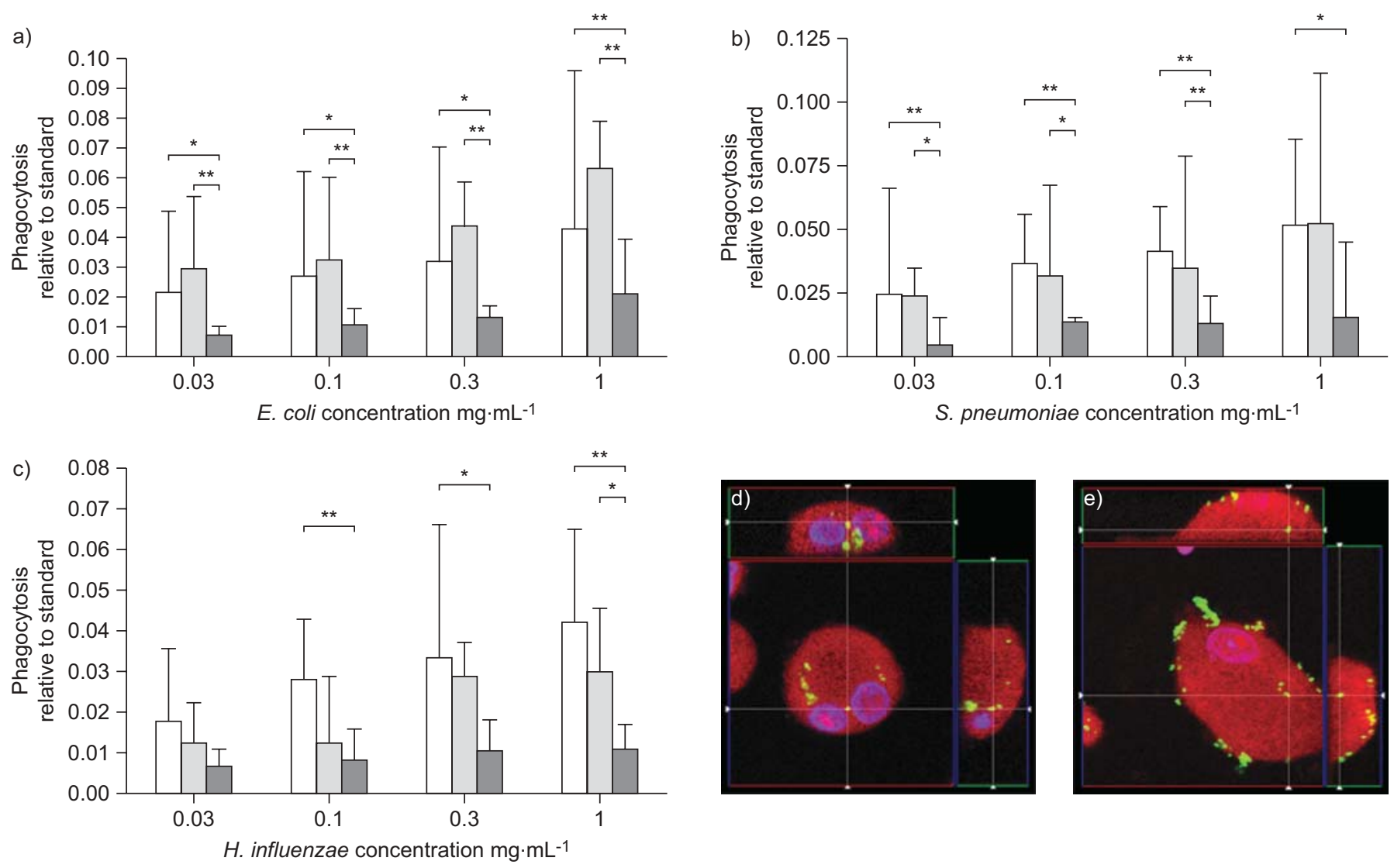

FIGURE 3. Phagocytic responses of monocyte-derived macrophages (MDM) from nonsmokers ( $\square$ ), smokers ( $\square$ ) and chronic obstructive pulmonary disease (COPD) patients $(\square)$ to pathogenic bacteria. MDM were generated from nonsmokers $(n=15-16)$, smokers $(n=13-14)$, and COPD patients $(n=16-17)$, and exposed to increasing concentrations of fluorescently labelled a) Escherichia coli, b) Streptococcus pneumoniae and c) Haemophillus influenzae for $1 \mathrm{~h}$. Phagocytosis was measured using a fluorometric plate reader. Data are presented as median \pm interquartile range. ${ }^{*}: p<0.05$; ${ }^{*}: p<0.01$. Internalisation of particles was confirmed using confocal microscopy. Representative orthogonal Z-stack views of phagocytosed d) S. pneumoniae and e) $H$. influenzae respectively.

structure (MARCO), phosphatidylserine (PS) receptor, human leukocyte antigen-DR (HLA-DR), toll-like receptor (TLR)2 and TLR4, all at $50 \mu \mathrm{g} \cdot \mathrm{mL}^{-1}$. The cells were washed twice with $\mathrm{PAB}$ and $\mathrm{a} \mathrm{F}(\mathrm{ab})^{\prime}{ }_{2}$ fragment of a phycoerythrin (PE)-labelled goat anti-mouse immunoglobulin (Ig)G $\left(20 \mu \mathrm{g} \cdot \mathrm{mL}^{-1}\right)$ (Dako Ltd, Ely, UK) was incubated with the cells for $30 \mathrm{~min}$ on ice. The cells were washed with PAB and finally resuspended in $300 \mu \mathrm{L}$ of FACSFlow $^{\mathrm{TM}}$ (Becton Dickinson, Oxon, UK) containing $0.5 \%(\mathrm{v} / \mathrm{v})$ formaldehyde prior to analysis on a FACScan cytometer (Becton Dickinson). 5,000 events were acquired and the fluorescence staining of the MDM was assessed at $575 \mathrm{~nm}$. The specific mean fluorescence (SMF) values were calculated as the fold difference of the mean fluorescence intensity (MFI) of the isotype control to the MFI of the test antibody.

\section{Statistical analysis}

Data are presented as mean \pm SEM for $n$ observations. Comparisons between subject groups or cell types were performed using Kruskal-Wallis analysis using GraphPad Prism software followed by Dunn's multiple comparison test (GraphPad Software Inc., San Diego, CA, USA) or a MannWhitney test where appropriate. Differences were considered significant where $\mathrm{p}<0.05$.

\section{RESULTS}

\section{Comparison of alveolar macrophage and MDM phagocytosis}

Initial experiments demonstrated that phagocytosis of polystyrene beads by both alveolar macrophages and MDM were similar (fig. 1a). Moreover, MDM from nonsmokers, smokers and COPD patients phagocytosed beads equally (fig. 1b) which was confirmed as internalisation by confocal microscopy (fig. 1c). This would indicate that the MDM model reflects alveolar macrophage phagocytosis and that inert particle removal is not altered in COPD. In order to ascertain whether similar responses were observed when macrophages were exposed to bacteria, a series of experiments were devised. Alveolar macrophages from COPD patients phagocytosed less E. coli compared with cells from nonsmokers and smokers (fig. 2a). By contrast, monocytes from each of the subject groups had low phagocytic responses that did not differ with either smoking or disease status (fig. 2b). However, MDM from COPD patients exhibited a reduced capacity to ingest bacteria similar to that of alveolar macrophages (fig. 2c). We confirmed this observation using fluorescence-activated cell sorting (FACS) analysis. Phagocytosis by MDM from nonsmokers and smokers were similar (figs $2 \mathrm{~d}$ and e) but cells from COPD patients exhibited a significant curve shift to the 

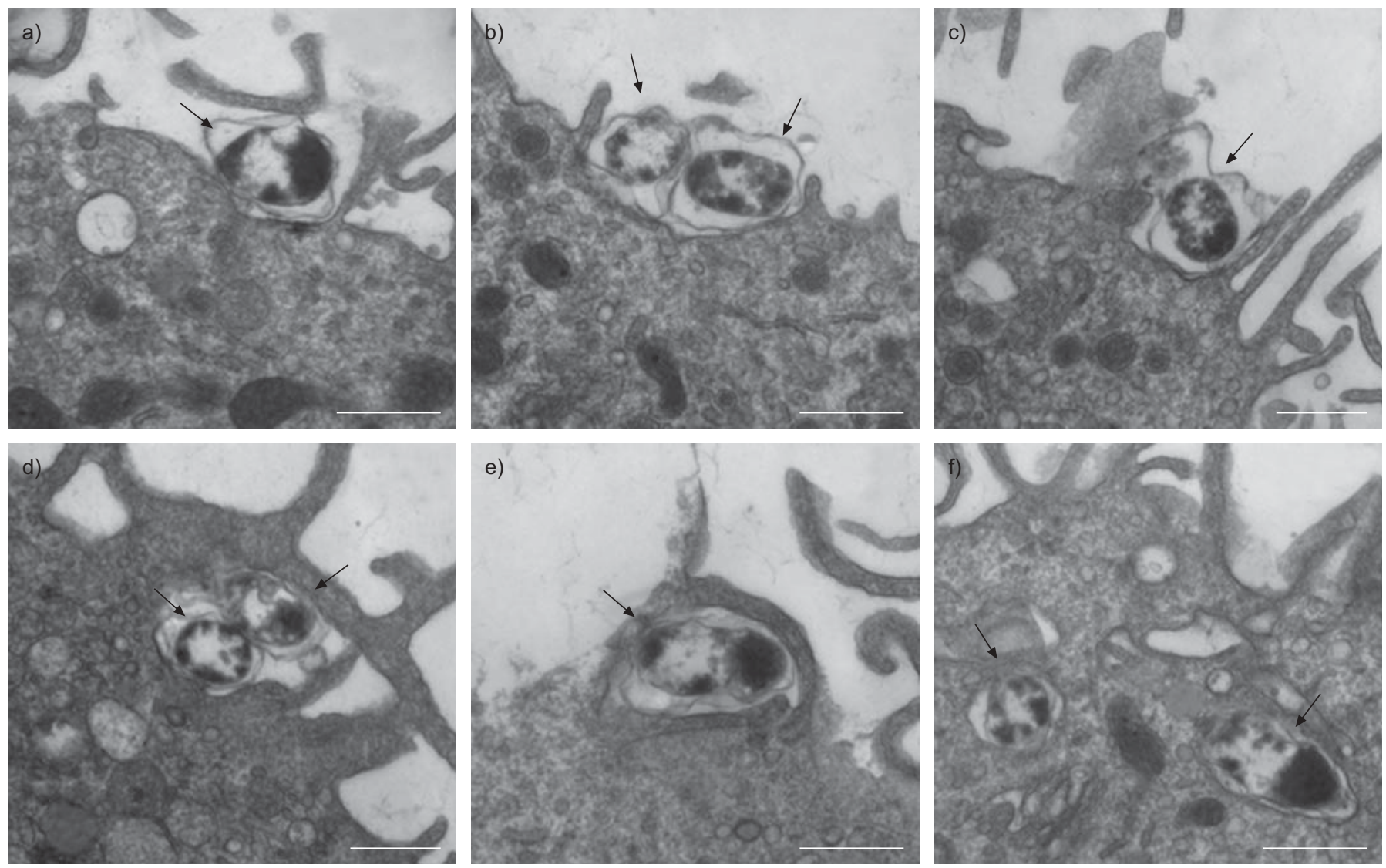

FIGURE 4. Electron microscopy images of monocyte-derived macrophages (MDM) phagocytosis of Haemophillus influenzae. MDM were generated from chronic obstructive pulmonary disease (COPD) patients and incubated with $1 \mathrm{mg} \cdot \mathrm{mL}^{-1} \mathrm{H}$. influenzae for $1 \mathrm{~h}$. Cells were then fixed, dehydrated and embedded in Araldite resin. Ultrathin slices were cut and stained, then viewed on a transmission electron microscope. Arrows indicate bacteria. a) A bacterium on the surface of an MDM; b and c) formation of phagocytic cups around bacteria; $d$ and e) this is proceeded by complete encapsulation by pseudopodia; and f) the bacteria are then transported into the cell cytoplasm within a phagosome. Scale bars $=500 \mathrm{~nm}$.

left (fig. 2f), indicating that fewer cells had engulfed bacteria. These comparative phagocytosis experiments suggest that, in COPD, defective macrophage phagocytosis is acquired during differentiation and that MDM may be useful for studying the underlying defective mechanism.

\section{MDM phagocytosis of $\mathrm{H}$. influenzae and $\mathrm{S}$. pneumoniae}

To investigate whether this reduced phagocytic response to bacteria was restricted to $E$. coli the phagocytic responses of MDM to fluorescently-labelled H. influenzae, S. pneumoniae and E. coli were evaluated. All MDM phagocytosed the three bacterial strains in a concentration-dependent manner (figs $3 a-c)$ but the response of COPD MDM was attenuated, not only towards E. coli (fig. 3a) but also for S. pneumoniae (fig. 3b) and $H$. influenzae (fig. 2c). To investigate whether defective phagocytosis in COPD MDM was an artefact of using heatkilled bacteria, experiments were devised using labelled, live bacteria. Under these conditions, MDM from control subjects phagocytosed increased $H$. influenzae and $S$. pneumoniae $(\mathrm{p}<0.05)$ compared with cells from COPD patients $(H$. influenzae: $3587 \pm 390$ versus $2170 \pm 166$ fluorescence units for control and COPD, respectively, $\mathrm{n}=9$; S. pneumoniae: $3885 \pm 344$ versus $2514 \pm 288$ fluorescence units for control and COPD, respectively, $\mathrm{n}=9$ ). Confocal microscopy confirmed internalisation of S. pneumoniae (fig. 3d) and H. influenzae (fig. 3e), and electron microscopy confirmed bacterial ingestion and formation of phagosomes (fig. 4) indicating that MDM from COPD patients have the capacity to mount correct phagocytic responses, albeit attenuated.

This reduced clearance of bacterial pathogens by macrophages may account for increased infections and the concomitant decline in lung function observed in COPD. Therefore, we next examined the relationship between lung function parameters and phagocytosis. Phagocytic responses of MDM to E. coli, H. influenzae or S.pneumoniae did not correlate with forced expiratory volume in $1 \mathrm{~s}$ (FEV1) \% predicted ( $\mathrm{r}=0.07$, $r=-0.05$ and $r=0.12$, respectively). Similarly, the FEV1/FVC ratio did not correlate with phagocytosis of E. coli, $H$. influenzae or S.pneumoniae ( $\mathrm{r}=-0.12, \mathrm{r}=-0.10$ and $\mathrm{r}=0.32$, respectively). In addition, there was no relationship between phagocytic response and current smoking status. Despite COPD patients having smoked more cigarettes than smokers and being older (see table 1) there were no correlations between either age or number of cigarettes smoked (pack-yrs) and phagocytosis of any bacteria examined.

\section{Cell surface expression of receptors involved in bacterial recognition}

There are numerous receptors involved in bacterial recognition by macrophages $[17,18]$, thus reduced receptor expression in 


\begin{tabular}{|c|c|c|c|}
\hline \multirow[t]{2}{*}{ TABLE 2} & \multicolumn{3}{|c|}{$\begin{array}{l}\text { Receptor expression on monocyte-derived } \\
\text { macrophages }\end{array}$} \\
\hline & Nonsmokers & Smokers & COPD \\
\hline \multicolumn{4}{|l|}{ HLA-DR } \\
\hline Expression \% & $92.4 \pm 2.9 ; n=5$ & $96.7 \pm 1.7 ; n=6$ & $93.6 \pm 1.7 ; n=12$ \\
\hline SMF & $9.8 \pm 4.3 ; n=5$ & $16.6 \pm 2.0 ; n=7$ & $12.8 \pm 2.2 ; n=12$ \\
\hline \multicolumn{4}{|l|}{ CD14 } \\
\hline Expression \% & $92.8 \pm 3.0 ; n=8$ & $97.5 \pm 1.3 ; n=5$ & $97.7 \pm 0.5 ; n=12$ \\
\hline SMF & $18.2 \pm 6.3 ; n=8$ & $20.2 \pm 2.4 ; n=5$ & $15.8 \pm 2.2 ; n=12$ \\
\hline \multicolumn{4}{|l|}{ TLR2 } \\
\hline Expression \% & $5.5 \pm 0.6 ; n=5$ & $7.7 \pm 4.6 ; n=8$ & $19.7 \pm 16.1 ; n=6$ \\
\hline SMF & $1.2 \pm 0.1 ; n=5$ & $1.4 \pm 0.3 ; n=8$ & $2.8 \pm 1.6 ; n=6$ \\
\hline \multicolumn{4}{|l|}{ TLR4 } \\
\hline Expression \% & $4.1 \pm 0.8 ; n=5$ & $2.1 \pm 0.4 ; n=8$ & $10.4 \pm 6.9 ; n=6$ \\
\hline SMF & $1.1 \pm 0.1 ; n=5$ & $1.0 \pm 0.1 ; n=8$ & $1.3 \pm 0.2 ; n=6$ \\
\hline \multicolumn{4}{|l|}{ CD163 } \\
\hline Expression \% & $21.1 \pm 4.1 ; n=7$ & $22.9 \pm 6.1 ; n=9$ & $18.8 \pm 2.2 ; n=5$ \\
\hline SMF & $6.0 \pm 0.7 ; n=7$ & $6.2 \pm 0.9 ; n=9$ & $4.6 \pm 0.6 ; n=5$ \\
\hline \multicolumn{4}{|l|}{ CD36 } \\
\hline Expression \% & $82.2 \pm 7.2 ; n=7$ & $87.6 \pm 3.0 ; n=9$ & $83.3 \pm 5.2 ; n=5$ \\
\hline SMF & $8.1 \pm 1.2 ; n=7$ & $7.4 \pm 1.1 ; n=9$ & $7.2 \pm 0.8 ; n=5$ \\
\hline \multicolumn{4}{|c|}{ Mannose receptor } \\
\hline Expression \% & $43.5 \pm 9.8 ; n=4$ & $51.2 \pm 14.0 ; n=8$ & $32.7 \pm 3.2 ; n=5$ \\
\hline SMF & $2.3 \pm 0.2 ; n=4$ & $3.6 \pm 0.6 ; n=8$ & $2.3 \pm 0.3 ; n=5$ \\
\hline \multicolumn{4}{|l|}{ MARCO } \\
\hline Expression \% & $7.5 \pm 1.2 ; n=4$ & $6.9 \pm 0.9 ; n=4$ & $5.9 \pm 0.6 ; n=5$ \\
\hline SMF & $2.3 \pm 0.2 ; n=4$ & $2.1 \pm 0.1 ; n=4$ & $1.7 \pm 0.3 ; n=5$ \\
\hline \multicolumn{4}{|l|}{ PS receptor } \\
\hline Expression \% & $58.2 \pm 4.6 ; n=7$ & $64.6 \pm 9.8 ; n=6$ & $47.9 \pm 0.8 ; n=5$ \\
\hline SMF & $2.7 \pm 0.3 ; n=7$ & $3.0 \pm 0.3 ; n=6$ & $2.4 \pm 0.1 ; n=5$ \\
\hline
\end{tabular}

Data are presented as mean \pm SEM; $n$. COPD: chronic obstructive pulmonary disease; HLA-DR: human lymphocyte antigen DR; CD: cluster of differentiation; SMF: specific mean fluorescence; TLR: toll-like receptor; MARCO: macrophage receptor with collagenous structure; PS: phosphatidylserine.

COPD could account for attenuated phagocytosis. However, there were no differences in the expression of TLR2, CD14, TLR4, or CD163 on MDM from COPD patients compared with cells from the other subject groups (table 2). There were also no differences in expression of non-specific scavenger receptors including the mannose receptor, MARCO or CD36 (table 2). Nor were there any differences in expression of the PS receptor or HLA-DR on these cells (table 2).

MDM from COPD patients phagocytosed beads normally (fig. 1b) limiting defective phagocytosis to engulfment of pathogenic bacteria. Since there were no differences in expression of a number of receptors considered important in recognition of non-opsonised particles (table 2), the downstream mechanisms emanating from receptor ligation that regulate phagocytic responses were examined. Pharmacological modulation of these pathways was utlilised to investigate whether altered signal transduction could account for these observations. The phosphoinositol-3-kinase inhibitor, LY-294002 and the p38 inhbitior, SB 203580, inhibited MDM phagocytosis of E. coli from all subjects similarly (figs S1a and c in the supplementary material). By contrast, the Rho kinase inhibitor, Y-27632, had no effect on phagocytosis at any of the concentrations tested (fig. S1b in the supplementary material).

\section{Effect of pharmacological agents on MDM phagocytosis}

COPD patients are currently taking a variety of medicaments to ameliorate their symptoms. These include glucocorticosteroids and bronchodilators. Therefore, it was possible that systemic effects of these drugs could alter the responses of blood-derived macrophages. To test this possibility, MDM from nonsmokers, smokers and patients with COPD were pretreated with various pharmacological agents prior to phagocytosis assay (fig. 5).

Exposure of MDM to budesonide improved the phagocytic responses of cells from COPD patients and smokers towards both $H$. influenzae and S. pneumoniae (figs $5 \mathrm{a}$ and d). Agents that elevate cAMP are considered to be inhibitory for phagocytosis [19]; however, formoterol did not inhibit phagocytosis of the bacteria in this system (figs $5 b$ and e) but stimulated the response of cells from smokers. There was no effect on the responses of cells derived from patients with COPD. The macrolide, azithromycin, is reported to restore the phagocytic response of alveolar macrophages from COPD patients and enable removal of apoptotic cells [20]; however, in this system, azithromycin had no effect on the response of cells from patients with COPD but improved the responses of cells from smokers (figs $5 \mathrm{c}$ and $\mathrm{f}$ ). Other drugs (tiotropium bromide $\left(10^{-9}-10^{-6} \mathrm{M}\right)$ or theophylline $\left.\left(10^{-8}-10^{-5} \mathrm{M}\right)\right)$ prescribed commonly to patients with COPD had no effect on the phagocytic response (data not shown).

\section{DISCUSSION}

Alveolar macrophages are the sentinel cell of the lung, patrolling the airways to remove any inhaled particles or pathogens. Failure of this innate response could lead to pulmonary damage and persistent infection. These are features of COPD and contribute to the worsening of disease. Therefore, this study examined, in detail, the phagocytic responses of macrophages to physiological lung pathogens in COPD.

Using a MDM model, we showed no difference in the capacity of cells from patients with COPD to remove inert particles. This confirms observations in alveolar macrophages from COPD patients where phagocytosis of inert beads occurs to the same extent as cells from control subjects $[12,21]$. However, we observed a very clear defect in the phagocytic response of MDM and alveolar macrophages from COPD patients to bacteria. This was not an artefact of using heat-killed bacteria, since we observed qualitatively similar data with live bacteria. Recently, alveolar macrophages from cigarette smokers have been shown to have a reduced phagocytic response for apoptotic epithelial cells that was associated with suppression of CD31, CD91, CD44 and CD71 [22]. The present study did not show any effect of smoking on the phagocytic response of MDM or alveolar macrophages for bacteria indicating that the mechanisms for apoptotic cell recognition and bacterial pathogens are quite distinct. Initial experiments using E. coli did not show a clear difference in the phagocytic response of MDM from smokers and COPD patients. However, a more detailed analysis using E. coli labelled "in-house" showed reduced phagocytosis of this bacterium between cells from 

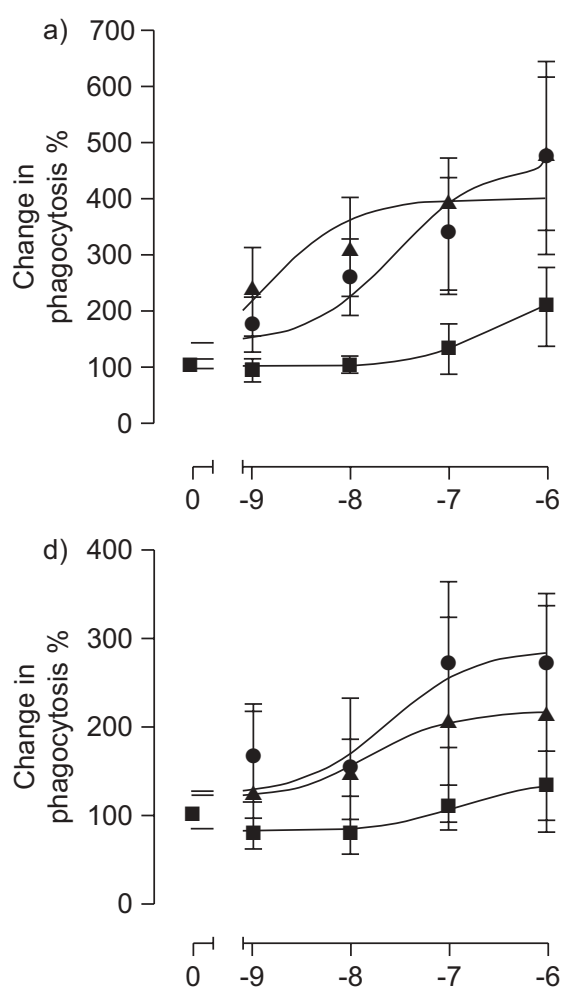

log budesonide concentration M
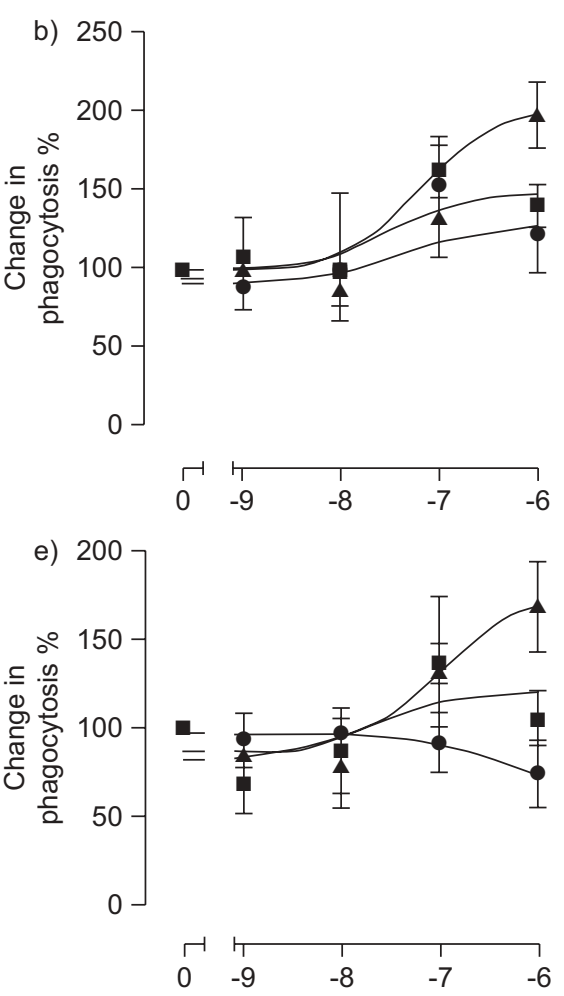

log formoterol concentration M
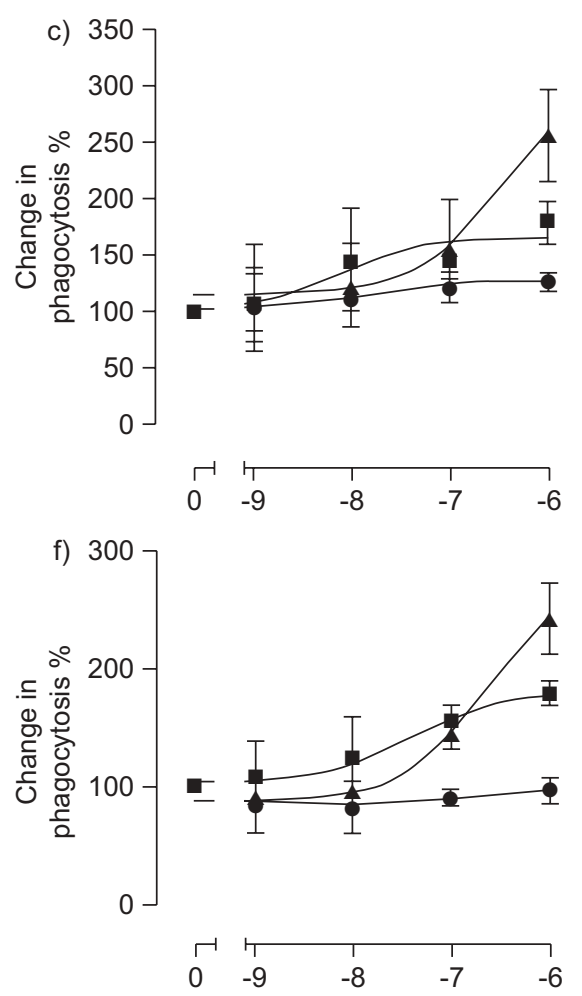

log azithromycin concentration M

FIGURE 5. Effects of pharmacological agents on phagocytosis of bacteria by monocyte-derived macrophages (MDM). MDM from nonsmokers ( $\mathbf{\square})$, smokers ( $\mathbf{\Lambda})$ and COPD patients $(\bullet$ ) were pre-treated with budesonide ( $a$ and d) or formoterol ( $b$ and e) for $1 \mathrm{~h}$, or azithromycin ( $\mathrm{c}$ and f) for $24 \mathrm{~h}$, prior to exposure of the cells to either $1 \mathrm{mg} \cdot \mathrm{mL}^{-1}$ Haemophillus influenzae $(\mathrm{a}-\mathrm{c})$ or Streptococcus pneumoniae $(\mathrm{d}-\mathrm{f})$ for $1 \mathrm{~h}$. Data were normalised to the phagocytosis response of each cell type in the absence of drug (100\%). Data are presented as mean \pm SEM $(n=5-6)$.

smokers and COPD patients. This discrepancy might reflect sensitivity of labelling between commercially obtained phagocytic prey and bacteria labelled in-house. Another study has suggested previously that alveolar macrophages from COPD patients phagocytose less $H$. influenzae compared with cells from smokers but not nonsmokers [14]. In contrast to our data, they reported no differences in responses of COPD MDM [14]. The reason for this discrepancy with our data is unclear but may reflect differences in the methods used to differentiate monocytes to MDM. Our methodology employed the use of GM-CSF which drives monocytes towards a more alveolar macrophage-like phenotype [23] and we also further validated our model by comparison with alveolar macrophages with respect to phagocytosis of polystyrene beads and E. coli.

Examination of the mechanism of reduced bacterial clearance by COPD macrophages led to investigation of cell surface molecules that could be responsible for recognition of bacteria leading to phagocytosis. However, these analyses indicated that various receptors were expressed similarly on MDM from all subject groups. This contrasts to reports that have shown that TLR2 is decreased on the surface of alveolar macrophages in smokers and patients with COPD [24]. Although, TLR may modulate the phagocytic response [25], the observation that removal of both Gram-positive and Gram-negative bacteria is reduced in COPD would suggest that these receptors are not pivotal in this response. Furthermore, the concept that reduced alveolar macrophage phagocytosis in COPD is due to cells becoming replete in the lung environment is unlikely as MDM differentiated in vitro show the same reduced response.

Investigation into the cell signalling pathways showed that phagocytosis was mediated by a phosphoinositide (PI)-3kinase-dependent mechanism but Rho kinase was unlikely to be involved. Rho kinase is critical in complement receptormediated but not Fc $\gamma$ R-mediated phagocytosis [26] and is inhibitory during phagocytosis of apoptotic cells [27]. As Y-27632 had no effect on phagocytosis of E. coli by MDM, the defective mechanism in COPD cells is likely to be distinct from that of apoptotic cells and complement opsonised particles. The inhibition of the phagocytic response by a nonselective PI-3-kinase inhibitor and a p38 inhibitor could limit the benefit of these agents as putative anti-inflammatory therapies in diseases, such as COPD, in which the phagocytic response is already suppressed.

Since this study utilised circulating cells that were subsequently differentiated, systemic levels of pharmacological agents used for the treatment of COPD may be responsible for the suppression of the phagocytic response observed in this study. However, none of the pharmaceutical agents examined suppressed phagocytosis of either H. influenzae or S. pneumoniae in cells from any of subject groups. Therefore, it is unlikely that differences in treatment regimes between the COPD patients and the control groups could account for the suppressed phagocytic response. It is of note that budesonide 
stimulated the phagocytic response in MDM obtained from patients with COPD. Although glucocorticosteroids do not improve the long-term decline in lung function observed in COPD patients, they have been shown to reduce exacerbation frequency [28]. This may be due to improved phagocytic responses of macrophages in the lungs of these patients. However, the concentrations of steroid required to significantly improve phagocytosis in vitro are high $\left(10^{-7}-10^{-6} \mathrm{M}\right)$ and, unlike alveolar macrophages from COPD patients, MDM do respond to steroids (data not shown).

In summary, MDM from COPD patients demonstrate reduced phagocytosis for common airway pathogens. This defect is specific to pathogenic bacteria. MDM from COPD patients are not replete, nor has differentiation occurred in a chronically inflamed lung, suggesting that lack of pathogen removal is an inherent defect in circulating monocytes from COPD patients that unmasks during maturation into macrophages. This defect in phagocytosis of bacteria that most frequently cause acute exacerbations of COPD is likely to be an important factor leading to colonisation of the lower airways and the propensity for bacterial exacerbations. Furthermore, the persistence of bacteria in the lower airways may act as a chronic antigenic drive for pulmonary inflammation and could contribute to the increased numbers of T- and B-lymphocytes in the airways of COPD patients [29]. Defining the molecular basis of this defect may lead to identification of susceptibility markers for airway obstruction in asymptomatic smokers and to development of novel therapies that stimulate phagocytic functions, leading to sterilisation of the respiratory tract and a reduction in the bacterial load that may drive chronic inflammation in COPD patients.

\section{SUPPORT STATEMENT}

This study was supported by the NIHR Respiratory Disease Biomedical Research Unit at the Royal Brompton and Harefield NHS Foundation Trust and Imperial College London, London, UK.

\section{STATEMENT OF INTEREST}

Statements of interest for P.J. Barnes and L.E. Donnelly can be found at www.erj.ersjournals.com/misc/statements.dtl

\section{REFERENCES}

1 Barnes PJ. Chronic obstructive pulmonary disease. N Engl J Med 2000; 343: 269-280.

2 Lopez AD, Shibuya K, Rao C, et al. Chronic obstructive pulmonary disease: current burden and future projections. Eur Respir J 2006; 27: 397-412.

3 Lindberg A, Eriksson B, Larsson LG, et al. Seven-year cumulative incidence of COPD in an age-stratified general population sample. Chest 2006; 129: 879-885.

4 Sethi S, Maloney J, Grove L, et al. Airway inflammation and bronchial bacterial colonization in chronic obstructive pulmonary disease. Am J Respir Crit Care Med 2006; 173: 991-998.

5 Wedzicha JA. Airway infection accelerates decline of lung function in chronic obstructive pulmonary disease. Am J Respir Crit Care Med 2001; 164: 1757-1758.

6 Makris D, Moschandreas J, Damianaki A, et al. Exacerbations and lung function decline in COPD: new insights in current and exsmokers. Respiratory Medicine 2007; 101: 1305-1312.

7 Andersson F, Borg S, Jansson SA, et al. The costs of exacerbations in chronic obstructive pulmonary disease (COPD). Respir Med 2002; 96: 700-708
8 Wedzicha JA, Wilkinson T. Impact of chronic obstructive pulmonary disease exacerbations on patients and payers. Proc Am Thorac Soc 2006; 3: 218-221.

9 Johansson A, Lundborg M, Skold CM, et al. Functional, morphological, and phenotypical differences between rat alveolar and interstitial macrophages. Am J Respir Cell Mol Biol 1997; 16: 582-588.

10 Culpitt SV, Rogers DF, Shah P, et al. Impaired inhibition by dexamethasone of cytokine release by alveolar macrophages from patients with chronic obstructive pulmonary disease. Am J Respir Crit Care Med 2003; 167: 24-31.

11 Russell RE, Culpitt SV, DeMatos C, et al. Release and activity of matrix metalloproteinase-9 and tissue inhibitor of metalloproteinase- 1 by alveolar macrophages from patients with chronic obstructive pulmonary disease. Am J Respir Cell Mol Biol 2002; 26: 602-609.

12 Hodge S, Hodge G, Scicchitano R, et al. Alveolar macrophages from subjects with chronic obstructive pulmonary disease are deficient in their ability to phagocytose apoptotic airway epithelial cells. Immunol Cell Biol 2003; 81: 289-296.

13 Prieto A, Reyes E, Bernstein ED, et al. Defective natural killer and phagocytic activities in chronic obstructive pulmonary disease are restored by glycophosphopeptical (inmunoferon). Am J Respir Crit Care Med 2001; 163: 1578-1583.

14 Berenson CS, Garlipp MA, Grove LJ, et al. Impaired phagocytosis of nontypeable haemophilus influenzae by human alveolar macrophages in chronic obstructive pulmonary disease. J Infect Dis 2006; 194: 1375-1384.

15 Tudhope SJ, Finney-Hayward TK, Nicholson AG, et al. Different mitogen-activated protein kinase-dependent cytokine responses in cells of the monocyte lineage. J Pharmacol Exp Ther 2008; 324: 306-312.

16 Russell RE, Thorley A, Culpitt SV, et al. Alveolar macrophagemediated elastolysis: roles of matrix metalloproteinases, cysteine, and serine proteases. Am J Physiol Lung Cell Mol Physiol 2002; 283: L867-L873.

17 Aderem A. Phagocytosis and the inflammatory response. J Infect Dis 2003; 187: S340-S345.

18 Aderem A, Underhill DM. Mechanisms of phagocytosis in macrophages. Annu Rev Immunol 1999; 17: 593-623.

19 Aronoff DM, Canetti C, Serezani $\mathrm{CH}$, et al. Cutting edge: macrophage inhibition by cyclic AMP (cAMP): differential roles of protein kinase A and exchange protein directly activated by cAMP-1. J Immunol 2005; 174: 595-599.

20 Hodge S, Hodge G, Brozyna S, et al. Azithromycin increases phagocytosis of apoptotic bronchial epithelial cells by alveolar macrophages. Eur Respir J 2006; 28: 486-495.

21 Martí-Lliteras P, Regueiro V, Morey $\mathrm{P}$, et al. Nontypeable Haemophilus influenzae clearance by alveolar macrophages is impaired by exposure to cigarette smoke. Infect Immun 2009; 77: $4232-4242$.

22 Hodge S, Hodge G, Ahern J, et al. Smoking alters alveolar macrophage recognition and phagocytic ability: implications in chronic obstructive pulmonary disease. Am J Respir Cell Mol Biol 2007; 37: 748-755.

23 Sulahian T, Imrich A, DeLoid G, et al. Signaling pathways required for macrophage scavenger receptor-mediated phagocytosis: analysis by scanning cytometry. Respir Res 2008; 9: 59.

24 Droemann D, Goldmann T, Tiedje T, et al. Toll-like receptor 2 expression is decreased on alveolar macrophages in cigarette smokers and COPD patients. Respir Res 2005; 6: 68.

25 Tricker E, Cheng G. With a little help from my friends: modulation of phagocytosis through TLR activation. Cell Res 2008; 18: 711-712.

26 Olazabal IM, Caron E, May RC, et al. Rho-kinase and myosin-II control phagocytic cup formation during CR, but not $F_{c} \gamma R$, phagocytosis. Current Biology 2002; 12: 1413-1418. 
27 Tosello-Trampont AC, Nakada-Tsukui K, Ravichandran KS. Engulfment of apoptotic cells is negatively regulated by Rhomediated signaling. J Biol Chem 2003; 278: 49911-49919.

28 Burge PS, Calverley PM, Jones PW, et al. Randomised, double blind, placebo controlled study of fluticasone propionate in patients with moderate to severe chronic obstructive pulmonary disease: the ISOLDE trial. BMJ 2000; 320: 1297-1303.

29 Hogg JC, Chu F, Utokaparch S, et al. The nature of small-airway obstruction in chronic obstructive pulmonary disease. $N$ Engl $J$ Med 2004; 350: 2645-2653. 